\title{
Synthesis of Bis(indolyl)methanes: A Natural Approach
}

\author{
MOHAMMED ZAMIR AHMED ${ }^{\mathrm{a}}$, C.B. KHILLARE ${ }^{\mathrm{b}}$ and SHAIKH KABEER AHMED ${ }^{\mathrm{a}}$ \\ ${ }^{a^{*}}$ P.G. Department of Chemistry, Sir Sayyad College of Arts, Commerce and Science, \\ Aurangabad-431001(M.S.) India \\ ${ }^{\mathrm{b}}$ P.G. Department of Chemistry, Maulana Azad College, Aurangabad- (M.S.) India \\ shaikh_kabeerahmed@rediffmail.com
}

Received 28 March 2013 / Accepted 30 April 2013

\begin{abstract}
An efficient and greener synthesis of bis(indoly)methanes was investigated via electrophilic substitution reaction of indole with carbonyl compounds in the presence of lemon juice as natural acid catalyst. The demonstrated environmentally benign protocol provided bis(indoly)methanes under mild reaction conditions, shorter reaction time and in excellent yield with simple work up procedure.
\end{abstract}

Keywords: Aldehydes, Ketones, Bis(indolyl)methanes, Natural catalyst

\section{Introduction}

The scaffolds with indole structures have been found to reflect the various applications in pharmaceuticals ${ }^{1}$, material sciences ${ }^{2} \&$ agrochemicals $^{3}$. The properties include cytotoxic, insecticidal, antibacterial etc. Acid catalyzed reactions of electron rich heterocycles such as pyrroles and indoles with $p$-dimethylaminobenzaldehyde is known as Ehrlich test ${ }^{4}$. And azafulvenium salts are produced by the analogous reaction of indoles with aromatic or aliphatic aldehydes and ketones. Further addition of second molecule of indole to azafulvenium salts gives bis(indolyl)methanes ${ }^{5}$. Indoles promote estrogen metabolism both in men \& women and also prevents the breast cancer ${ }^{6}$. Literature data reveals that various catalytic systems were employed for the synthesis of bis(indolyl)methanes such as protic acids ${ }^{7}$ or Lewis acids ${ }^{8}$ via electrophilic substitution reaction of indoles with substituted aromatic or aliphatic aldehydes or ketones. However, lewis acids are required in excess because it is destroyed by the presence of even small mount of moisture or when trapped by nitrogen present in heterocycles 9 . With the aim to find out neat methodology for the synthesis of bis(indolyl)methanes various chemists employed different catalysts ${ }^{10-30}$ summarized in Table 1. Though the synthesis of bis(indolyl)methanes achieved by various protocols but still we realize the need of an efficient method which avoid the use perilous solvents, expensive catalytic systems and longer reaction time. Synthesis of bis(indolyl)methanes is also achieved in the absence of catalyst using protic solvents ${ }^{12}$ but with great sacrifice of time. 
In continuation of our studies to develop neat methodologies in synthetic chemistry ${ }^{10,29-31}$, we have investigated here an efficient and environmentally benign protocol for the condensation reaction of indole with various carbonyl compounds to synthesize bis(indolyl)methanes using lemon juice as natural acid catalyst.

\section{Experimental}

The required chemicals were purchased from S.D. fine chemicals (India). Melting points were determined by an open capillary method and are uncorrected. The IR spectra were recorded on Shimadzu FT-IR 157 spectrophotometer. ${ }^{1} \mathrm{H}$ NMR spectra were recorded using $\mathrm{CDCl}_{3}$ or DMSO- $d_{6}$ as solvent and TMS as an internal standard either on Brucker $300 \mathrm{MHz}$ or $400 \mathrm{MHz}$ NMR spectrophotometer. The chemical shift values are expressed in part per million (ppm). The mass spectra were recorded on EI-Shimadzu-GC-MS spectrometer. The purity of the synthesized compounds was checked by thin layer chromatography (TLC) technique on silica gel plate using hexane and ethyl acetate (9:1).

\section{General procedure for the synthesis of bis(indolyl)methanes (3a-q)}

To a mixture of indole $(2 \mathrm{mmol})$ and 4-chloro benzaldehyde $(1 \mathrm{mmol})$ taken in round bottom flask was added $5 \mathrm{~mL}$ of lemon juice and the reaction mixture was stirred at room temperature for $20 \mathrm{~min}$. The progress of reaction was checked by TLC. After consumption of reactants, water was added to the reaction mixture and filtered. The crude product so obtained was purified by column chromatography (Ethyl acetate: Hexane, 1:9). All the synthesized compounds were confirmed by comparing their physical and spectral analysis data found in the literature.

\section{3,3'- Bis(indolyl)phenyl methane (Entry 1, 3a)}

Solid, M.P.: 150-155 ${ }^{0}$ C; IR (KBr)cm ${ }^{-1}: 3387,3047,2957,2927,1482,1456,1340,1095$, 736 ; ${ }^{1} \mathrm{H} \mathrm{NMR}\left(\mathrm{CDCl}_{3}, 300 \mathrm{MHz}\right): 5.90(\mathrm{~s}, 1 \mathrm{H}), 6.65(\mathrm{~s}, 2 \mathrm{H}), 7.00(\mathrm{t}, 2 \mathrm{H}), 7.20-7.24(\mathrm{~m}, 3 \mathrm{H})$, 7.29-7.31(m, 2H), 7.33-7.37(m, 6H), 7.95(brs, $2 \mathrm{H})$.

\section{3,3'-Bis(indolyl)-4-nitrophenyl methane (Entry 6, 3e)}

Solid, M.P.: 216-218 ${ }^{0} \mathrm{C}$; IR $(\mathrm{KBr}) \mathrm{cm}^{-1}: 3420,3050,1595,1510,1455,1340 . ;{ }^{1} \mathrm{H}$ NMR $\left(\mathrm{CDCl}_{3}, 300 \mathrm{MHz}\right): 5.98(\mathrm{~s}, 1 \mathrm{H}), 6.70(\mathrm{~s}, 2 \mathrm{H}), 7.00-7.05(\mathrm{~m}, 3 \mathrm{H}), 7.35(\mathrm{~d}, 3 \mathrm{H}), 7.40(\mathrm{~d}, 2 \mathrm{H})$, 7.50(d, 2H), 8.05(brs, 2H), 8.15(d, 2H).

\section{3,3'-Bis(indolyl)-4-methyl phenyl methane (Entry 11, 3k)}

Solid, M.P.: $94-96{ }^{0} \mathrm{C}$; IR (KBr) $\mathrm{cm}^{-1}: 3410,3040,2930,1600,1510,1215,1050,775 . ;{ }^{1} \mathrm{H}$ $\mathrm{NMR}\left(\mathrm{CDl}_{3}, 300 \mathrm{MHz}\right): 2.35(\mathrm{~s}, 3 \mathrm{H}), 5.85(\mathrm{~s}, 1 \mathrm{H}), 6.70(\mathrm{~s}, 2 \mathrm{H}), 7.05(\mathrm{t}, 2 \mathrm{H}), 7.1(\mathrm{~d}, 2 \mathrm{H}), 7.25-$ 7.29(m, 6H), 7.5(d, 2H), 7.98(brs, 2H).

\section{Results and Discussion}

We have demonstrated the condensation of indole with various carbonyl compounds via electrophilic substitution reaction affording bis(indolyl)methanes by employing lemon juice as natural acid catalyst.

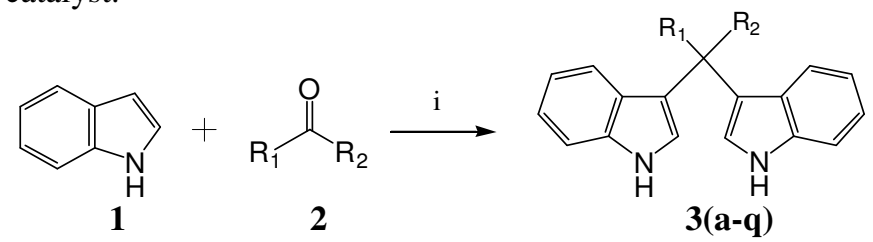

Scheme 1. Reaction Conditions: i) Lemon juice, (Const.stir, rt, 20 min) 
Lemon juice extract is not only worked as a catalyst but also as solvent media. The reaction was carried out at room temperature via stirring. The completion of the reaction was realized within $20 \mathrm{~min}$ (progress of the reaction was monitored by TLC) affording moderate to good yield of bis(indolyl)methanes. We made a successful attempt to explore the efficiency of the methodology towards various aromatic aldehydes with electron withdrawing, releasing and alpha beta unsaturated substituents and ketones. The results are summarized in Table 2 .

Various catalytic systems under different reaction conditions were reported ${ }^{10-30}$ with an intention to develop efficient methodology for the synthesis of bis(indolyl)methanes (Table 1). But, the literature data acknowledged us about the poor reactivity of ketones and aromatic aldehydes with electron withdrawing substituents towards the condensation reaction with indole in presence of various catalytic systems.

In our investigation, we observed the smooth applicability of the protocol with various substituted aromatic aldehydes. However, ketones required longer reaction times when compared with substituted aromatic aldehydes. The same behavior of ketones towards this reaction is observed regarding various catalytic systems. However, in our previous report ${ }^{30}$ we have performed this reaction without use of any catalyst via grinding technique, it required more than $12 \mathrm{~h}$ for the completion of reaction with the formation of by products, hence the poor yield of bis(indolyl)methanes (8-10\%) was reported.

Table 1. Condensation reaction of indole with various carbonyl compounds to synthesize bis(indolyl)methanes using various catalytic systems and reaction conditions

\begin{tabular}{|c|c|c|c|c|c|c|}
\hline Entry & Catalysts & Solvents & $\begin{array}{l}\text { Temp., } \\
{ }^{0} \mathrm{C}\end{array}$ & Time, $\mathrm{h} / \min$ & $\begin{array}{c}\text { Yield }^{\mathrm{b}} \\
\%\end{array}$ & Ref \\
\hline 1 & $\mathrm{InF}_{3} \cdot \mathrm{H}_{2} \mathrm{O}$ & Aqueous & r.t & $10-15 \mathrm{~h}$ & 99 & {$[10]$} \\
\hline 2 & $\operatorname{Ln}(\mathrm{OTf})_{3}$ & $\mathrm{EtOH} / \mathrm{H}_{2} \mathrm{O}$ & r.t & $12 \mathrm{~h}$ & 98 & [11] \\
\hline \multirow[t]{2}{*}{3} & NO & a) $\mathrm{MeOH}$ & r.t & $4-20 \mathrm{~h}$ & 75 & {$[12]$} \\
\hline & & b) $\mathrm{H}_{2} \mathrm{O}$ & r.t & $1-5 \mathrm{~h}$ & 90 & \\
\hline 4 & {$[\mathrm{BMIM}] \mathrm{BF}_{4}$} & Solvent free & 100 & $4 \mathrm{~h}$ & trace & {$[13]$} \\
\hline 5 & $\mathrm{Zn}\left(\mathrm{HSO}_{4}\right)$ & $\mathrm{EtOH}$ & r.t & $3-6 h$ & 92 & [14] \\
\hline 6 & CAN & $\mathrm{EtOH}$ & r.t & $2-5 \mathrm{~h}$ & 96 & [15] \\
\hline 7 & Amberlyst-15 & DCM & r.t & $3 \mathrm{~h}$ & 89 & [16] \\
\hline 8 & $\mathrm{ZrOCl}_{2} \cdot 8 \mathrm{H}_{2} \mathrm{O} /$ Silica gel & -- & 50 & 20-180 min & 94 & [17] \\
\hline 9 & SSA & Solvent free & r.t & $1-6 h$ & 95 & {$[18]$} \\
\hline 10 & MontmorilloniteK-10 & Solvent free & r.t & $1-6 \mathrm{~h}$ & 97 & [19] \\
\hline 11 & $\mathrm{Sb}_{2}\left(\mathrm{SO}_{4}\right)_{3}$ & $\mathrm{MeOH}$ & r.t & $1.3 \mathrm{~h}$ & 90 & [20] \\
\hline 12 & Zeolite & DCM & r.t & $1 \mathrm{~h}$ & 85 & [21] \\
\hline 13 & $\mathrm{ZnO}$ & Solvent free & 80 & $45 \mathrm{~min}$ & 98 & [22] \\
\hline 14 & $\mathrm{NaBF}_{4}$ & Solvent free & r.t & $45 \mathrm{~min}$ & 90 & [23] \\
\hline 15 & Sulfamic acid & Solvent free & r.t & $30 \mathrm{~min}$ & 95 & [24] \\
\hline 16 & 15-ZTPA & Solvent free & 60 & $30 \mathrm{~min}$ & 90 & [25] \\
\hline 17 & Phosphated zirconia & Solvent free & 80 & $20 \mathrm{~min}$ & 95 & {$[26]$} \\
\hline 18 & 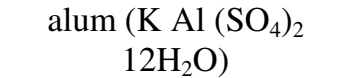 & Solvent free & r.t & $10 \mathrm{~min}$ & 92 & {$[27]$} \\
\hline 19 & $\mathrm{HBF}_{4}-\mathrm{SiO}_{2}$ & Solvent free & r.t & $10 \mathrm{~min}$ & 94 & [28] \\
\hline 20 & $\mathrm{I}_{2}$ & $\mathrm{CH}_{3} \mathrm{CN}$ & r.t & $1 \mathrm{~min}$ & 99 & [29] \\
\hline 21 & $\mathrm{SnCl}_{2} \cdot 2 \mathrm{H}_{2} \mathrm{O}$ & Solvent free & r.t & $1 \mathrm{~min}$ & 99 & [30] \\
\hline
\end{tabular}


Table 2. Lemon juice catalyzed condensation reaction of indole with various carbonyl compounds to synthesize the corresponding bis(indolyl)methanes

\begin{tabular}{|c|c|c|c|c|}
\hline Entry & Indole 1 & Carbonyl compounds 2 & BIM 3(a-q) & Yield, \% ${ }^{a, b}$ \\
\hline 1 & 1 & $\mathrm{PhCHO}$ & 3a & 77 \\
\hline 2 & 1 & 4-OMePhCHO & $3 \mathbf{b}$ & 75 \\
\hline 3 & 1 & 4-ClPhCHO & $3 c$ & 80 \\
\hline 4 & 1 & 2-ClPhCHO & $3 e$ & 76 \\
\hline 5 & 1 & $2,4-\mathrm{Cl}_{2} \mathrm{PhCHO}$ & 3d & 74 \\
\hline 6 & 1 & $4-\mathrm{NO}_{2} \mathrm{PhCHO}$ & 3f & 75 \\
\hline 7 & 1 & $2-\mathrm{NO}_{2} \mathrm{PhCHO}$ & $3 g$ & 78 \\
\hline 8 & 1 & 4-OH PhCHO & 3h & 70 \\
\hline 9 & 1 & 2-OH PhCHO & $3 \mathbf{i}$ & 76 \\
\hline 10 & 1 & 4-Br $\mathrm{PhCHO}$ & 3j & 72 \\
\hline 11 & 1 & 4-Me PhCHO & $3 \mathbf{k}$ & 74 \\
\hline 12 & 1 & $\mathrm{PhCH}=\mathrm{CH}-\mathrm{CHO}$ & 31 & 69 \\
\hline 13 & 1 & $\mathrm{CH}_{3}\left(\mathrm{CH}_{2}\right)_{4}-\mathrm{CHO}$ & $3 \mathrm{~m}$ & 71 \\
\hline 14 & 1 & $\mathrm{CH}_{3}\left(\mathrm{CH}_{2}\right)_{5}-\mathrm{CHO}$ & $3 n$ & 70 \\
\hline 15 & 1 & MeCOMe & 30 & 69 \\
\hline 16 & 1 & $\mathrm{MeCOPh}$ & $3 \mathbf{p}$ & 70 \\
\hline 17 & 1 & $-\left(\mathrm{CH}_{2}\right)_{5}-\mathrm{CO}$ & $3 q$ & 68 \\
\hline
\end{tabular}

BIM- Bis (indolyl) methanes, ${ }^{a}$ Yield of the isolated pure product, ${ }^{b}$ Products were compared with authentic samples

\section{Conclusion}

In the present investigation, we put forth here an efficient and environmentally benign synthesis of bis(indolyl)methanes at room temperature by employing lemon juice as a natural acid catalyst. The efficiency of the methodology towards various carbonyl compounds with ease of work up procedure, fast reaction rate and the excellent yield are of ample evidence to draw the attention of the chemists.

\section{Acknowledgment}

The authors are also thankful to UGC, New Delhi for providing financial assistance for the research work.

\section{References}

1. Sundberg R J, Academic Press, New York, 1970.

2. Minne S C, Manalis S R and Quate C F, Appl Phys Lett., 1995, 67(26), 3918-3920.

3. Plimmer J R, Gammon D W and Ragsdale N N, John Wiley and Sons, New York, 2003, 3 .

4. Weis C D, J Org Chem., 1962, 27(10), 3693-3695; DOI: 10.1021/jo01057a512.

5. Jones R and Bean G P, Academic press, London, 1977.

6. Karthik M, Tripathi A K, Gupta N M and Murugeson V, Catal Commun., 2004, 5, 371-375 \& cited papers.

7. (a) Auria M, Tetrahedron, 1991, 47(44), 9225-9230; (b) Kamal A and Qureshi A A, Tetrahedron, 1963, 19(4), 513-520.

8. Babu G, Sridhar N and Perumal P T, Synth Commun., 2000, 30(9), 1609-1614.

9. Kobayashi S, Araki M and Yasuda M, Tetrahedron Lett., 1995, 36(32), 5773-5776. 
10. Bandgar B P and Shaikh K A, J Chem Res., 2004, 34-36.

11. Depu.Chen S, Libing Yu and Wang P G, Tetrahedron Lett., 1996, 37(26), 4467-4470.

12. Deb M L and Bhuyan P J, Tetrahedron Lett., 2006, 47(9), 1441-1443.

13. KuroshR M and Masoumeh Sharifi-Kiasaraaie, Tetrahedron, 2009, 65(43), 8816-8820.

14. Niknam K, Zolfigol M A, Sadabadi T and Nejati A, J Iranian Chem Soc., 2006, 3(4), 318-322.

15. Zeng X F, Ji S J and Wang S Y, Tetrahedron, 2005, 61(43), 10235-10241.

16. Chimmani R, Banerjee J, Pal R and Das B, Adv Synth Catal., 2003, 345(3), 557-559.

17. Firouzabadi H, Iranpoor N, Jafarpoor M and Ghaderi A, J Mol Catal A: Chem., 2006, 253(1-2), 249-251.

18. Pore D M, Desai U V, Thopate T S and Wadgaonkar P P, Arkivoc., 2006, 12, 75-80.

19. Chakrabarthy M, Ghosh N, Basak R and Harigaye Yoshihiro, Tetrahedron Lett., 2002, 43(22), 4075-4078.

20. Srinivasa A, Varma P P, Hulikal V J and Mahadevan K M, Monatshefte fur Chemie, 2008, 139, 111-115.

21. Reddy A V, Ravinder K, Reddy V L N, Goud T V, Ravikanth V and Venkateswarlu Y, Synth Commun., 2003, 33(21), 3687-3694.

22. Mona Hosseini-Sravari, Synth Commun., 2008, 38, 832-840.

23. Kamble V T, Bandgar B P and Bavikar S N, Chin J Chem., 2007, 25(1), 13-15.

24. Tao A L, Ding F Q, Zou J P, Lu X H and Zhang L L, Chin J Chem., 2007, 25(6), 822-827.

25. Satam J R, Parghi K D and Jayaram R V, Catal Commun., 2008, 9(6), 1071-1078.

26. Nadkarni S V, Gawande M B, Jayaram R V and Nagarkar J M, Catal Commun., 2008, 9(8), 1728-1733.

27. Sonar S S, Sadaphal S S, Kategaonkar A H, Pokalwar R U, Shingate B B and Shingare M S, Bull Korean Chem Soc., 2009, 30(4), 825.

28. Bandgar B P, Patil A V and Kamble V T, Arkivoc., 2007, 16, 252-259.

29. Bandgar B P and Shaikh K A, Tetrahedron Lett., 2003, 44, 1959-1961.

30. Shaikh K A, Mohammed Z A, Patel N T, Syed S A and Vishal A Patil, RJPBCS 2010, 1(4), 730-736.

31. (a) Mohammed Zamir Ahmed, Patel N T, Shaikh K A, Baseer M A, Shaikh Shahid and Vishal A Patil, Elixir Org Chem., 2012, 43, 6583-6585; (b) Mohammed Zameer Ahmed, Patel N T, Shaikh K A, Kendre M M, Shaikh Shahid and Baseer M A, J Chem Cheml Sci., 2012, 2(1), 13-19. 